\title{
Production of Amorphous Fe-Ni Based Alloys by Flame-Spray Quenching
}

\author{
By Harumatsu Miura*, Shigeteru Isa*, Keisuke Omuro**, \\ and Nozomu Tanigami***
}

\begin{abstract}
A study of the production of amorphous alloys by a flame-spray quenching in air was performed on the $\left(\mathrm{Fe}_{1-x} \mathrm{Ni}_{x}\right)_{80} \mathrm{P}_{14} \mathrm{~B}_{6}$ alloy system with $0.1 \leq x \leq 0.9$. The spray-quenching system was composed basically of the spray gun of the oxyacetylene type and the water-cooled copper plate as the cold substrate. To make the quenching more effective, the gun traverse rate was moderately controlled and the argon gas blowing around the flame and the liquid carbon dioxide blowing on the substrate were additionally done. The spray-quenched alloy samples were examined to check the progress of glass formation mainly by X-ray diffraction and differential scanning calorimetry.

By controlling the gun traverse rate much faster than that in the ordinary spraying practice and by doing the argon blowing adequately to adjust the flame temperature as well as to suppress oxidation of the metal stream, the effect of quenching was remarkably improved. It was found that by means of the liquid carbon dioxide blowing, oxidation of the deposit alloy was prevented due to the carbon dioxide gas-shielding effect being generated on the substrate and hence effectiveness of the quenching itself was strikingly improved.

When only control of the gun traverse rate and the argon gas blowing of these additional operations were performed on a series of nine alloys in the spray-quenching, amorphous flakes were easily obtained in all but the alloys with $x \leq 0.3$. Furthermore, by carring out the carbon dioxide blowing together with the above operations, also an amorphous sheet about $150 \mu \mathrm{m}$ thick of the $\mathrm{Fe}_{40} \mathrm{Ni}_{40} \mathrm{P}_{14} \mathrm{~B}_{6}$ alloy was prepared without difficulty.

The flame-spray quenching method presented in this paper appears to be able to be applied also for production of thicker amorphous alloy sheets as well as their flakes in quantities in a wide variety of alloy systems, prepared to be homogeneous in composition, including the present alloy system by further improvement of spray-quenching conditions.
\end{abstract}

(Received December 20, 1980)

\section{Introduction}

When a thermal spray gun is used as a liquid metals source in the production of amorphous alloys by rapid quenching from the melt, there are, for instance, several advantages that (1) the gun has a substantially large source of the melt; (2) it requires no crucible for melting; (3) there are hardly damages of its nozzle due to the melt owing to the mechanism of the gun in the spraying process; (4) hence it can con-

* Department of Iron and Steel Engineering, Iron and Steel Technical College, Nishikoya, Amagasaki 661, Japan.

** Department of Mechanical Engineering, Iron and Steel Technical College, Nishikoya, Amagasaki 661, Japan.

*** Faculty of Science and Technology, Kinki University, Higashi-Osaka 577, Japan. Present Address: Ebara Electronics Co., Ltd., Takarazuka 665, Japan. tinuously supply the melt in a somewhat large scale for a relatively long time and is more favorable especially in case of metals with high melting points.

As a cold substrate for rapid-quenching of the liquid metal stream from the gun in the spraying process, we can consider use of the substrates of the stationary type and the moving type. While preparation of the amorphous alloy by use of the former type has not been reported so far except that of the present authors $^{(1)(2)}$, there have been studies on preparation of amorphous alloy sheets by using the latter type, which were carried out by Giessen et $a l .^{(3)}$, Shingu et $a .^{(4)}$ and the present authors ${ }^{(1)(2)}$. Giessen et al. have prepared an amorphous alloy sheet of the composition $\mathrm{Cu}_{60} \mathrm{Zr}_{40}$ using a rotating copper disc water-cooled as the substrate and the plasma-spray gun, and also Shingu et al. and the present authors, the amorphous alloy sheet of $\mathrm{Fe}_{40} \mathrm{Ni}_{40} \mathrm{P}_{14} \mathrm{~B}_{6}$ using a rotating copper 
drum cooled with liquid nitrogen and a flamespray gun of the oxyacetylene type. Besides studies described as above, those on rapid cooling of sprayed deposit alloys were presented in several papers ${ }^{(5)-(7)}$, but these did not aim at the preparation itself of amorphous alloys, and in all these studies very expensive plasmaspray guns were employed as in case of Giessen et al.

The purpose of the present study is to produce bulk amorphous sheets and flakes in quantities, which are difficult to obtain by conventional processes, of practical alloys such as $\mathrm{Fe}-\mathrm{Ni}$ based ones by effective rapidquenching of the molten alloy stream from the spray gun of the oxyacetylene type. In case of the amorphous sheet, however, it is prerequisite to its production that each flaky product, formed on the substrate in an instant when liquid metal streams from the gun impinge upon the substrate, entirely changes into the amorphous state, since the amorphous sheet is formed by successive building-up of such flakes on the substrate according to the mechanism of its formation. Even in case in which it is difficult to obtain the amorphous sheet by building-up of such flakes because of less glass formability of alloys spray-quenched, if amorphous alloy flakes can be produced in quantities by this process, the production itself is very valuable from the practical point of view, since, e.g. applications of the products fabricated by consolidation of such amorphous flakes may be expected.

By performing effectively additional operations such as the argon blowing around the flame and the cryogen gas blowing on the substrate area in the spray qenching system, which consists of the flame-spray gun of the oxy-acetylene type and the cold substrate of the stationary type or the moving one, we have tried to produce the bulk sheets and flakes of the amorphous $\mathrm{Fe}-\mathrm{Ni}$ based alloys like $\mathrm{Fe}_{40} \mathrm{Ni}_{40} \mathrm{P}_{14} \mathrm{~B}_{6}$ alloy.

The present paper reports results and informations obtained, as described above, in the trial production of the amorphous flakes and sheets of $\left(\mathrm{Fe}_{1-x} \mathrm{Ni}_{x}\right)_{80} \mathrm{P}_{14} \mathrm{~B}_{6}$ alloy by using the water-cooled copper plate as the cold substrate in the spray-quenching system.

\section{Experimental Procedure}

\section{Preparation of alloy powder}

The Fe-Ni based alloys of nine kinds of composition $\left(\mathrm{Fe}_{1-x} \mathrm{Ni}_{x}\right)_{80} \mathrm{P}_{14} \mathrm{~B}_{6}$ (at.pct.) were used which were prepared at regular intervals of $x=$ 0.1 except the alloy with $x=0.675$. The powder of the alloys was prepared by comminution and shieving of $9 \mathrm{~mm}$ thick ingot produced from electrolytic iron $(99.9 \% \mathrm{Fe})$, pure nickel pellets $(99.97 \% \mathrm{Ni}), \mathrm{Fe}-\mathrm{P}$ alloy $(26.1 \% \mathrm{P})$, and $\mathrm{Fe}-\mathrm{B}$ alloy $(21.17 \% \mathrm{~B})$ by induction-melting and chill-casting in argon atmosphere. It was sized in the $60-100 \mu \mathrm{m}$ range to be applicable to the flame-spray quenching.

\section{Flame-spray quenching system}

The flame-spray quenching system used consists basically of the flame-spray gun (Metco 5P type Thermospray Gun), using combustion heat of acetylene and oxygen as a heat source, and the water-cooled copper plate $(280 \mathrm{~mm} \times$ $170 \mathrm{~mm} \times 20 \mathrm{~mm}$ ) as a cold substrate, as schematically shown in Fig. 1. To make the quenching and gas-shielding on the substrate more effective, the cryogen blowing device is attached to the substrate as illustrated in the figure. In the present work, the liquid carbon dioxide was mainly employed as a cryogen like this.

As shown in the figure, the argon gas was blown from the front nozzle of the gun around the flame so as to envelop it in order to reduce adequately its temperature and to depress the oxidation of the metal stream. Main sprayquenching conditions selected were as follows:

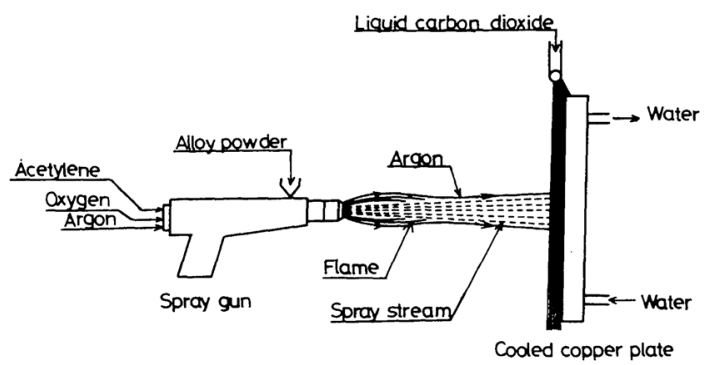

Fig. 1 Schematic representation of spray-quenching system. 
Spraying performed in air, gun-substrate distance $0.50 \mathrm{~m}$, ordinary gun traverse rate $1.00 \mathrm{~m} / \mathrm{s}$, powder ejecting hole $\dagger$ diameter $\approx 10^{-3} \mathrm{~m}$, acetylene flow rate $2.61 \times 10^{-4}$ $\mathrm{m}^{3} / \mathrm{s}$, oxygen flow rate $4.72 \times 10^{-4} \mathrm{~m}^{3} / \mathrm{s}$, powder feed rate $2.52 \mathrm{~g} / \mathrm{s}$, argon blow rate $8.00 \times 10^{-4} \mathrm{~m}^{3} / \mathrm{s}$, liquid carbon dioxide blow rate $4.71 \mathrm{~g} / \mathrm{s}$, molten alloy stream temperature $\approx 2400-2600 \mathrm{~K} \dagger \dagger$, cooling rate $\approx 10^{6} \mathrm{~K} / \mathrm{s} \dagger \dagger \dagger$.

\section{Check on the progress of glass formation of spray-quenched alloys}

To begin with, all the spray-quenched alloy samples were analyzed by X-ray diffraction. Next, differential scanning calorimetry (DSC) was made on each sample representing the typical amorphous halo-pattern in the above X-ray diffractometry, to determine the heat, $\Delta H_{\mathrm{c}}$, evolved on crystallization and the temperature, $T_{\mathrm{x}}$, at which the sample crystallizes, in the heating scan. In this way, the quenched samples were examined not only structurally but also energitically on the progress of glass formation. $\Delta H_{c}$ was calculated from a peak area of the DSC curve, i.e. by weighing the part of paper of that area cut out from the chart. $T_{\mathrm{x}}$ was given as the extrapolatedonset temperature, i.e. the intersection of a line extrapolated through the straight line portion of the DSC curve toward its peak with the base line.

The X-ray diffraction analyses were done

$\dagger$ Nozzle P7G (Metco part code, powder thermospray type) was used which had ten powder ejecting holes and ten gas flame ejecting holes positioned in radial symmetry, respectively, on the inner side and the outer one of its front.

$+\dagger$ Estimated from the fact that solid pure alumina $\left(99.9 \% \mathrm{Al}_{2} \mathrm{O}_{3}\right)$ began to melt in several seconds in the flame, and from the maximum temperature ordinarily obtained in the oxyacetylene flame.

$\dagger \dagger \dagger$ Estimated on the basis of the theoretical consideration, given in the literature ${ }^{(8)}$, that for amorphous alloys if the reduced glass temperature $\left(T_{\mathrm{g}} / T_{\mathrm{m}}\right)=0.5$, a cooling rate of $10^{6} \mathrm{~K} / \mathrm{s}$ is required to quench a melt into a glassy state; the value of $T_{\mathrm{g}} / T_{\mathrm{m}}$ of the present alloy system is estimated to be 0.5 or so since the $T_{\mathrm{x}} / T_{\mathrm{m}^{-}}$ value in this system is about $0.55-0.59$, as shown in Fig. 3 later, considering the value of $T_{\mathrm{g}}$ is somewhat smaller than that of $T_{\mathbf{x}}$. with $\mathrm{CoK}_{\alpha}$-radiation in the range of the diffraction angle, $2 \theta, 0.7854$ to $1.0647 \mathrm{rad}$ [ $45^{\circ}(\pi / 180)$ to $\left.61^{\circ}(\pi / 180) \mathrm{rad}\right]$, showing the most intensive diffraction peaks in crystalline state of the present alloy system. Differential scanning calorimetry was performed with DSC unit in the Du Pont 990 Analyser. Samples weighing 10-20 mg were heated at $8.33 \times 10^{-2}$ $\mathrm{K} / \mathrm{s}$ in the flowing argon gas $\left(8.33 \times 10^{-1}\right.$ $\mathrm{cm}^{3} / \mathrm{s}$ ). A reference material used was pure aluminum, and a calibration of heat was done by using the heats of fusion of zinc, lead, tin, and indium standards.

\section{Results and Discussion}

\section{Glass formability of the} $\left(\mathrm{Fe}_{1-x} \mathrm{Ni}_{x}\right)_{80} \mathbf{P}_{14} \mathbf{B}_{6}$ alloys

In order to examine the glass formability of the alloy system $\left(\mathrm{Fe}_{1-x} \mathrm{Ni}_{x}\right)_{80} \mathrm{P}_{14} \mathrm{~B}_{6}$, the quenched flaky samples of nine compositions, as mentioned in the previous Section II.1, were prepared under the same condition by use of the spray-quenching equipment shown in Fig. 1. In this case, the spray-quenching of each alloy was done only by the water-cooled copper plate without performing additional operations such as the argon blowing and the cryogen gas blowing. The gun traverse rate was $0.70 \mathrm{~m} / \mathrm{s}$; it was controlled slower than that in the ordinary case to make clearer the difference of the glass formability between the present alloys. Samples obtained were flakes of $20-30 \mu \mathrm{m}$ in thickness and about $0.6 \mathrm{~mm}$ in width and 1 $\mathrm{mm}$ in length at the most.

Figure 2 shows a typical X-ray diffraction. pattern for each quenched sample. Here, the pattern designated by $*$ is that of the amorphous alloy "Metglas 2826," prepared by the Allied Chemical Co., of the same composition as the one of the sample with $x=0.5$ in the present alloy system. In the figure, while for the alloys with $0.4 \leq x \leq 0.8$ nearly halopatterns typical of the amorphous material are observed, there appear some peaks representing the partial crystallinity in the patterns for those with $x \leq 0.3$ and $x=0.9$. Therefore, in this alloy system, it seems that whereas the former alloys are relatively easy 


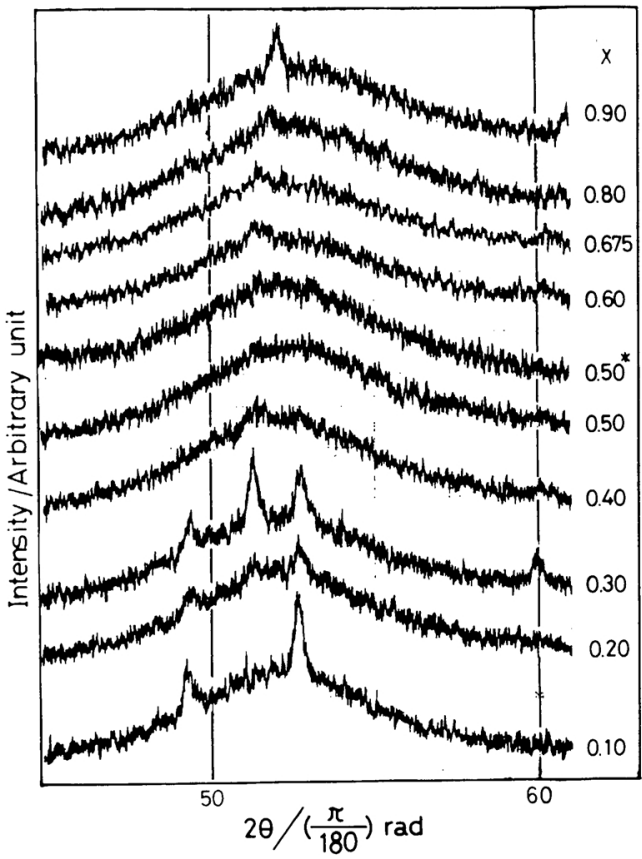

Fig. 2 X-ray diffraction patterns for flaky $\left(\mathrm{Fe}_{1-x}\right.$ $\left.\mathrm{Ni}_{x}\right)_{80} \mathrm{P}_{14} \mathrm{~B}_{6}$ alloys spray-quenched on the watercooled copper plate at the rate of gun traverse of $0.70 \mathrm{~m} / \mathrm{s}$ (CoK $\alpha$-radiation).

* Obtained from the analysis for the amorphous alloy "Metglas 2826", prepared by the Allied Chemical Co.

to change into the amorphous state on sprayquenching, the latter are not so easy to change, because of their less glass formability.

Generally, as a measure of representing easiness of glass formation, the reduced glass temperature is used and alloys having the higher reduced glass temperatures are taken to be more favorable for the formation of amorphous alloys. Although the reduced glass temperature is given as the ratio of the glass temperature $T_{\mathrm{g}}$ to the melting temperature $T_{\mathrm{m}}$ of the alloy considered, for the glassy alloy the ratio of the crystallization temperature $T_{\mathrm{x}}$ to the melting temperature $T_{\mathrm{m}}$, i.e. the reduced crystallization temperature, $T_{\mathrm{x}} / T_{\mathrm{m}}$, may be employed as its approximation since the difference between $T_{\mathrm{g}}$ and $T_{\mathrm{x}}$ is not too large, in common, for such alloys.

In Fig. 3 the ratio $T_{\mathrm{x}} / T_{\mathrm{m}}$ of the present alloy system is plotted against the value of $x$. Here the values of the ratio $T_{\mathrm{x}} / T_{\mathrm{m}}$ were determined by using those of $T_{\mathrm{x}}$ and $T_{\mathrm{m}}$ obtained from the

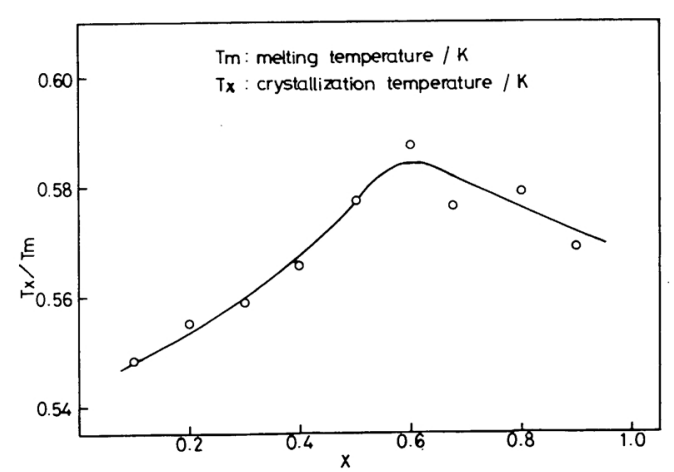

Fig. 3 Composition dependence of reduced crystallization temperature $\mathrm{T}_{\mathrm{x}} / \mathrm{T}_{\mathrm{m}}$ of $\left(\mathrm{Fe}_{1-x} \mathrm{Ni}_{x}\right)_{80} \mathrm{P}_{14} \mathrm{~B}_{6}$ alloys.

differential scanning calorimetry described in the preceding Section II.3 and the differential thermal analysis respectively for spray-quenched samples of this alloy system. In the differential thermal analysis, the high purity $\alpha-\mathrm{Al}_{2} \mathrm{O}_{3}$ was used as a reference material, and calibration of the temperature was done by use of the $\alpha$ to $\beta$ transformation point of quartz. The figure indicates that the glass forming tendency is largest near $x \cong 0.6$ and becomes small with deviation from this value. This is considered roughly to explain the results obtained by the X-ray diffraction trace in Fig. 2, though there seems some discrepancy between the composition corresponding to the maximum value of $T_{\mathrm{x}} / T_{\mathrm{m}}$ and the one showing the largest glass forming tendency in the X-ray diffraction patterns of Fig. 2 probably since $T_{\mathrm{x}} / T_{\mathrm{m}}$ was approximately employed as a measure of glass formability

Furthermore, the tendency of composition dependence of glass formation, shown in Fig. 2, is thought substantially to correspond to the following results presented by Polk and Chen ${ }^{(9)}$ from the $\mathrm{X}$-ray diffraction traces for the roller quenched $\left(\mathrm{Fe}_{1-x} \mathrm{Ni}_{x}\right)_{77} \mathrm{P}_{14} \mathrm{~B}_{6} \mathrm{Al}_{3}$ alloy. That is, in their work, shortly speaking, the 12.5 at $\%$ and 25 at $\% \mathrm{Ni}$ alloys were slightly crystalline, the 37.5 at $\%$ to 75 at $\% \mathrm{Ni}$ alloys were amorphous, and the 87.5 at $\% \mathrm{Ni}$ alloy was partially crystalline.

\section{Preparation of amorphous alloy flake}

Using the $\left(\mathrm{Fe}_{0.7} \mathrm{Ni}_{0.3}\right)_{80} \mathrm{P}_{14} \mathrm{~B}_{6}$ alloy, which 


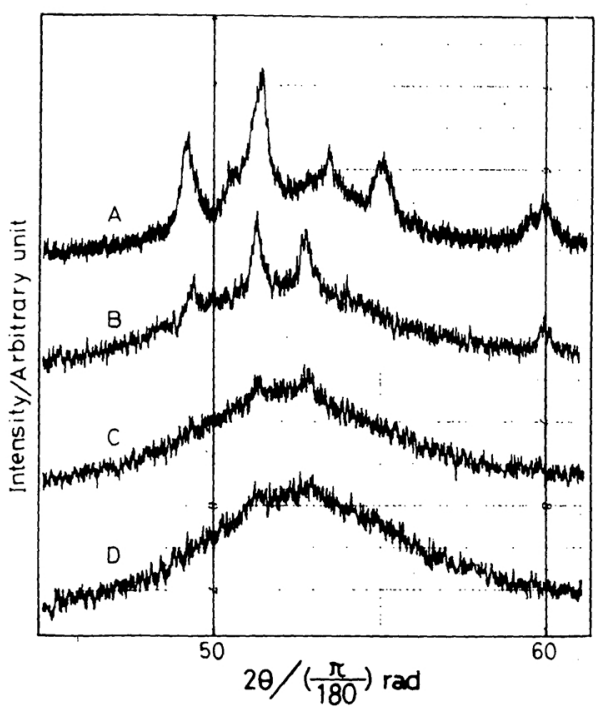

Fig. 4 X-ray diffraction patterns for flaky $\left(\mathrm{Fe}_{0.7}\right.$ $\left.\mathrm{Ni}_{0.3}\right)_{80} \mathrm{P}_{14} \mathrm{~B}_{6}$ alloys spray-quenched at the following gun traverse rate. A: $0.40 \mathrm{~m} / \mathrm{s}$. B: $0.70 \mathrm{~m} / \mathrm{s}$. C, D: $1.00 \mathrm{~m} / \mathrm{s}$. Also in case of $\mathrm{D}$ the argon blowing was additionally performed at the rate of $8.00 \times$ $10^{-4} \mathrm{~m}^{3} / \mathrm{s}$.

revealed a relatively small glass-forming tendency upon spray-quenching, several quenched samples were prepared under some different quenching conditions, and the relationship between the progress of glass formation and the quenching conditions was examined from results of X-ray diffraction traces.

Figure 4 exhibits typical X-ray diffraction patterns for quenched samples obtained from the above experiment. In this figure, A, B and $\mathrm{C}$ were designated for expressing the following gun traverse rates chosen in the respective cases. A: $0.40 \mathrm{~m} / \mathrm{s}$. B: $0.70 \mathrm{~m} / \mathrm{s}$. C: $1.00 \mathrm{~m} / \mathrm{s}$. The designation $\mathrm{D}$ was also used to express that the gun traverse rate was the same as that of $\mathrm{C}$ and that the argon blowing for flamecontrolling was done in this case. As seen in the figure, the progress of glass formation was in the order D, C, B and A, and in case of D the almost-halo pattern typical of amorphous material was observed. Although the operation at the gun traverse rate faster than $1.00 \mathrm{~m} / \mathrm{s}$ was technically possible, in such a condition. the spray stream began to deflect and rather did not result in good performance. Therefore the upper limit of the effective gun traverse rate was considered to be about $1.00 \mathrm{~m} / \mathrm{s}$ in the present quenching system. In addition, the difference in form of flakes was hardly recognized when the gun traverse rate was varied in the range $0.40-1.00 \mathrm{~m} / \mathrm{s}$.

The effects of the gun traverse rate-and the flame-controlling on the progress of glass formation were revealed in all the sample alloys studied. That is, by performing such controls upon spray-quenching, the typical amorphous halo patterns were obtained, on the $\mathrm{X}$-ray diffraction examination, in all but the alloys with $x \leq 0.3$ which represented some weak peaks, indicating the slight crystallinity as in $\mathrm{D}$ in Fig. 4.

Thus it is clear that the quenching condition is remarkably improved by carring out not only the control of the gun traverse rate but also the argon gas blowing. The reason for promoting the glass formation by the argon gas blowing is that its blowing can moderately reduce the temperature of the superheated metal stream and the flame. In this case, the glass formation was promoted with increasing blow rate up to the rate of about $8.00 \times 10^{-4}$

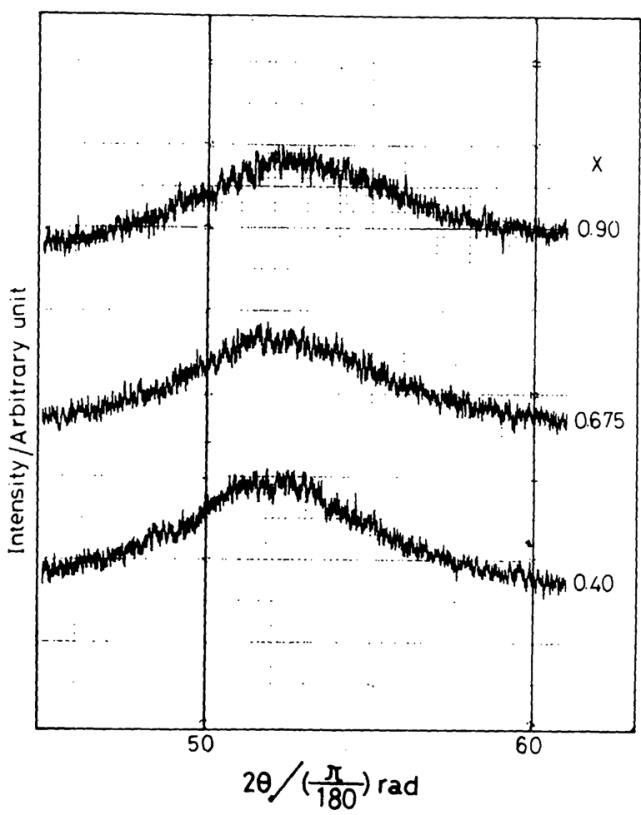

Fig. $5 \mathrm{X}$-ray diffraction patterns for several flaky $\left(\mathrm{Fe}_{1-x} \mathrm{Ni}_{x}\right)_{80} \mathrm{P}_{14} \mathrm{~B}_{6}$ alloys spray-quenched under the following improved condition. Gun traverse rate: $1.00 \mathrm{~m} / \mathrm{s}$. Argon blow rate: $8.00 \times 10^{-4} \mathrm{~m}^{3} / \mathrm{s}$. 
$\mathrm{m}^{3} / \mathrm{s}$. However, in the present quenching system, increasing the argon blow rate larger than this was not effective for further progress of glass formation, though the reason is uncertain. The same blowing effect will be produced also in case of the use of other inert gases than argon gas.

Figure 5 shows such typical halo patterns in the X-ray diffraction traces for several samples produced by the above-mentioned quenching.

Moreover, the above-quenched samples revealing the typical amorphous halo-patterns were thermally analyzed by DSC traces, and it was observed that these samples crystallized near $673-773 \mathrm{~K}$, upon heating, evolving the latent heat. Figure 6 indicates a typical DSC curve for the $\mathrm{Fe}_{40} \mathrm{Ni}_{40} \mathrm{P}_{14} \mathrm{~B}_{6}$ alloy with $x=$ 0.5 . By analyzing the DSC curve like this in terms of the method described in the earlier Section II.3, the crystallization temperature $T_{\mathrm{x}}$ and the heat of crystallization $\Delta H_{\mathrm{c}}$ for the sprayquenched $\mathrm{Fe}_{40} \mathrm{Ni}_{40} \mathrm{P}_{14} \mathrm{~B}_{6}$ alloy were determined to be $681 \mathrm{~K}$ and $-4.63 \mathrm{~kJ} / \mathrm{mol}$ respectively. The value of $T_{\mathrm{x}}$ thus obtained is fairly taken to correspond to the one, i.e., $673 \mathrm{~K}$, given by Polk and Chen ${ }^{(9)}$ from the DSC analysis for

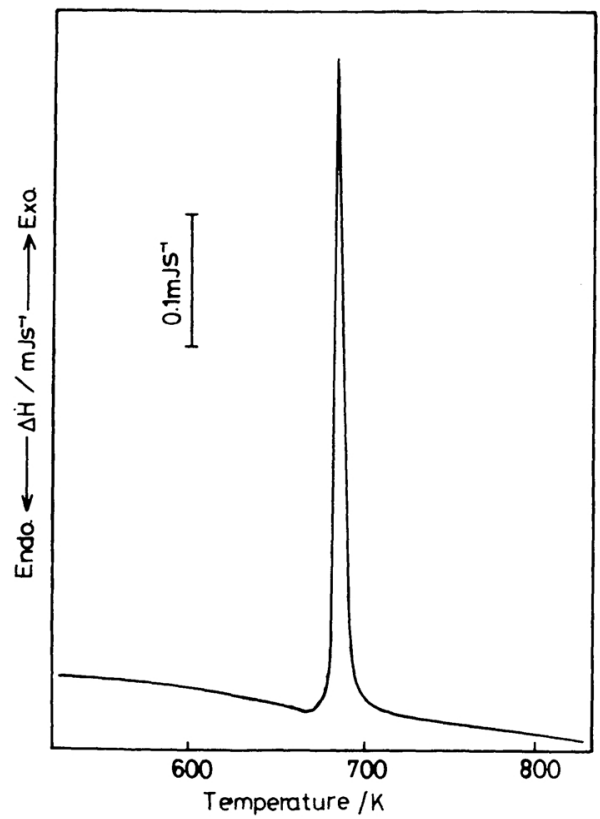

Fig. 6 DSC curve for the spray-quenched flaky alloy $\mathrm{Fe}_{40} \mathrm{Ni}_{40} \mathrm{P}_{14} \mathrm{~B}_{6}$ representing the typical amorphous halo-pattern in its X-ray analysis. the roller-quenched $\mathrm{Fe}_{40} \mathrm{Ni}_{40} \mathrm{P}_{14} \mathrm{~B}_{6}$.

In the amorphous alloy, the value of $\Delta H_{\mathrm{c}}$ is said to be $30 \%$ or so of its heat of fusion $\Delta H_{\mathrm{m}}$ at the melting temperature $T_{\mathrm{m}}{ }^{(10)}$. Assuming that the melting of $\mathrm{Fe}_{40} \mathrm{Ni}_{40} \mathrm{P}_{14} \mathrm{~B}_{6}$ alloy can be taken to occur at the almost constant temperature since its melting temperature is relatively high and the melting itself takes place in the narrow temperature range near $T_{\mathrm{m}}$, $\Delta H_{\mathrm{m}}$ is approximately determined as the melting temperature $T_{\mathrm{m}}$ times the entropy of fusion of the alloy $\Delta S_{\mathrm{m}}$ calculated additively from the entropies of fusion of the constituent elements of it (i.e., $\Delta H_{\mathrm{m}} \cong T_{\mathrm{m}} \Delta S_{\mathrm{m}}$ ). Calculation of the value of $\Delta H_{\mathrm{m}}$ of $\mathrm{Fe}_{40} \mathrm{Ni}_{40} \mathrm{P}_{14} \mathrm{~B}_{6}$ alloy resulted in $10.46 \mathrm{~kJ} / \mathrm{mol}$. Consequently, the value of $\Delta H_{\mathrm{c}}$ given as above is about $40 \%$ of $\Delta H_{\mathrm{m}}$. This value is considered to correspond to the heat of solidification. The value of $\Delta H_{c}$ of any of other quenched alloys, obtained in the DSC trace as exhibited in Fig. 6, was in the range of -4.50 to $-5.00 \mathrm{~kJ} / \mathrm{mol}$. These values are also thought to correspond to the heats of solidification.

Thus, all the six flaky alloy samples with $\geq 0.4$ as shown in Fig. 5 are judged to be amorphous from the results of both the analyses as above, i.e. the structural and the energitical analysis performed by X-ray diffraction and DSC respectively.

\section{Preparation of amorphous alloy sheet}

In order to find the effective method of sprayquenching for production of amorphous alloy sheets, experiments described below have been made on the $\mathrm{Fe}_{40} \mathrm{Ni}_{40} \mathrm{P}_{14} \mathrm{~B}_{6}$ alloy, which seems to be easiest to form the glass in the present alloy system, by employing the sprayquenching equipment shown in Fig. 1. In this case the spray-quenched deposit alloy itself must be effectively rapid-cooled by the adequate cryogen, as shown in Fig. 1, to be capable of working as the sufficient cold substrate for next arrivals as well as of suppressing the crystallization of the deposit alloy due to its reheating by the successive flame and metal stream from the gun.

Figure 7 shows typical X-ray diffraction patterns for the free surface of the sprayquenched $\mathrm{Fe}_{40} \mathrm{Ni}_{40} \mathrm{P}_{14} \mathrm{~B}_{6}$ alloy sheets about 


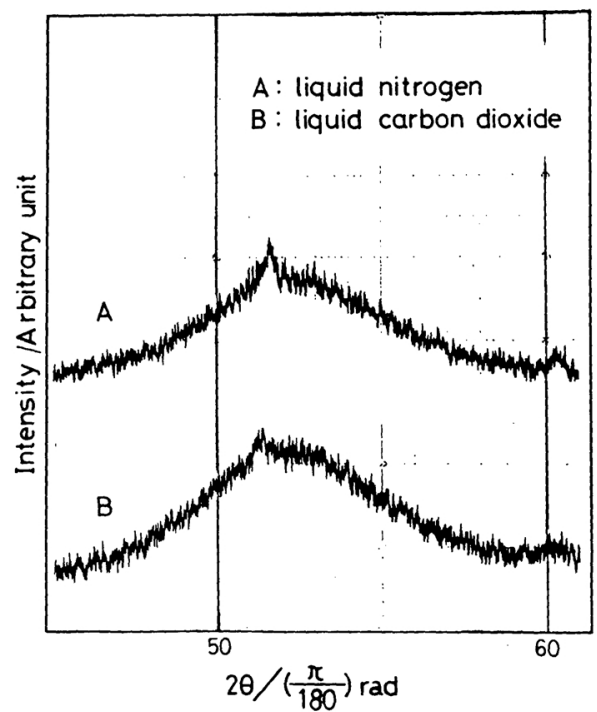

Fig. 7 X-ray diffraction patterns for free surfaces of the $\mathrm{Fe}_{40} \mathrm{Ni}_{40} \mathrm{P}_{14} \mathrm{~B}_{6}$ alloy sheets spray-quenched under liquid nitrogen-or liquid carbon dioxideblowing on the substrate.

$150 \mu \mathrm{m}$ thick and $30 \mathrm{~mm}$ wide prepared by using liquid nitrogen $(6.24 \mathrm{~g} / \mathrm{s})$ or liquid carbon dioxide $(3.34 \mathrm{~g} / \mathrm{s})$ as the above-mentioned cryogen together with the argon blowing, at the rate of $8.00 \times 10^{-4} \mathrm{~m}^{3} / \mathrm{s}$, around the flame as performed in the flaky sample preparation, in the spray-quenching equipment depicted in Fig. 1. Here, both cryogens blowing on the substrate was carried out by using the same nozzle which was made of the copper pipe $(8 \mathrm{mmID} \times 300 \mathrm{mmL})$ with the cryogen-ejecting holes $1.5 \mathrm{~mm}$ in diameter at regular intervals along its longitudinal direction. The above blow rates of liquid nitrogen and carbon dioxide indicate the respective values in the case that these were controlled so as to keep the moderate and appreciably violent blowing onto the substrate, i.e., onto the sprayed area by using the same nozzle described above.

As seen in the figure, liquid carbon dioxide, as compared with liquid nitrogen, was more effective in quenching in this equipment, though it could not be unconditionally said whether the former is better or not than the latter because the effectiveness of the cryogen depends also on the way of its use. This is considered to be due to the fact that when liquid carbon dioxide is employed as a cryogen it is actually ejected from the nozzle not in the liquid state, as seen frequently in case of the liquid nitrogen, but in the gaseous state at low temperature. That is, such cold gaseous carbon dioxide can be uniformly blown over all the substrate area and also its flow rate is easily controlled to be more effective during the sprayquenching. Although liquid nitrogen was also capable of being ejected in the gaseous state from the nozzle by decreasing its blow rate, the gaseous cryogen effect as noticed above could not be expected by use of it because, in the present quenching system, it was difficult to obtain the moderately high gas pressure of nitrogen as in the carbon dioxide. Thus it may be expected that utility of liquid carbon dioxide results in good performance regardless of its temperature much higher than that of the liquid nitrogen. Furthermore, since liquid carbon dioxide used as a cryogen is practically blown in the state of cryogen cold gas, as mentioned above, on the substrate, frosting onto the substrate, as seen frequently when liquid nitrogen was employed, did not occur even in case in which its blowing on the substrate was being carried out just before spraying. Therefore it was, in practice, much more convenient to use liquid carbon dioxide than liquid nitrogen. Also in case of the use of liquid carbon dioxide, there is another advantage that the entire surface of the substrate, that is, the spray-deposited layer is shielded by the cold carbon dioxide gas blast (i.e., by the air curtain effect) from the air to prevent its oxidation.

To examine such an effect of preventing the oxidation of the sprayed alloy deposit, the spray-quenched alloy sheets with $x=0.1$, which might be perhaps easiest to suffer the oxidation in the present alloy system because of their high iron concentration, were prepared under the same quenching condition as that of $\mathrm{B}$ in Fig. 7 and the brightness of the free surfaces of sheet samples was measured by Silicon Light Sensor. Here, taking the brightness of the sample with $x=0.1$, reduction-treated by hydrogen gas, as unity, that of the as-quenched sheet samples was given to be $1.00 \pm 0.03$, and hence the significant difference between them was not recognized. Therefore, it appears that 
the oxidation of the alloy deposit does not almost occur during the spray-quenching. This method of shielding the alloy deposit by the cryogen cold gas from the air may be more effective especially when it is applied to alloy systems relatively easy to suffer the oxidation during the spray-quenching.

We discuss here the mechanism of formation of the spray-quenched sheet of the $\mathrm{Fe}_{40} \mathrm{Ni}_{40} \mathrm{P}_{14} \mathrm{~B}_{6}$ alloy. In this alloy, amorphous flakes were easily obtained only by quenching the melt from the gun on the water-cooled copper plate as indicated in Fig. 2. Accordingly, when the deposited sheet is very thin at the initial stage, the glass formation seems to proceed fully by quenching the melt only with the aid of the water-cooled copper plate. This viewpoint is supported also from the fact that the substrate face of quenched sheet showed typical amorphous halo-patterns in its X-ray diffraction analysis for any sample sheet as well as samples, marked A and B in Fig. 7. Therefore, it is also considered that the crystallization of the amorphous phase once formed, due to its reheating by the flame and spray stream, does not take place under the spray-quenching condition like this. However, as the quenched alloy layer becomes increasingly thick with the successive deposit of the spray stream, quenching of the melt will tend to be done by a new substrate having less heat conductivity, namely, the as-quenched alloy deposit itself rather than the copper substrate and by the cryogen gas blown on the substrate. Consequently, at this stage, even though such cryogen blowing was carried out, the quenching rate will much largely decrease, compared with that of the initial stage in which the melt is directly quenched by the copper substrate. In such a case, some crystallinity seems to be partially involved in the deposit spray-quenched at this stage, because of the quenching unsufficient to proceed the full glass formation. Some peakes revealing partial crystallinity in the X-ray diffraction patterns of Fig. 7 appear for such reason as stated above.

In order to raise further the effect of quenching by the substrate and cryogen itself and to proceed fully the glass formation of the quenched $\mathrm{Fe}_{40} \mathrm{Ni}_{40} \mathrm{P}_{14} \mathrm{~B}_{6}$ alloy sheet, the blow

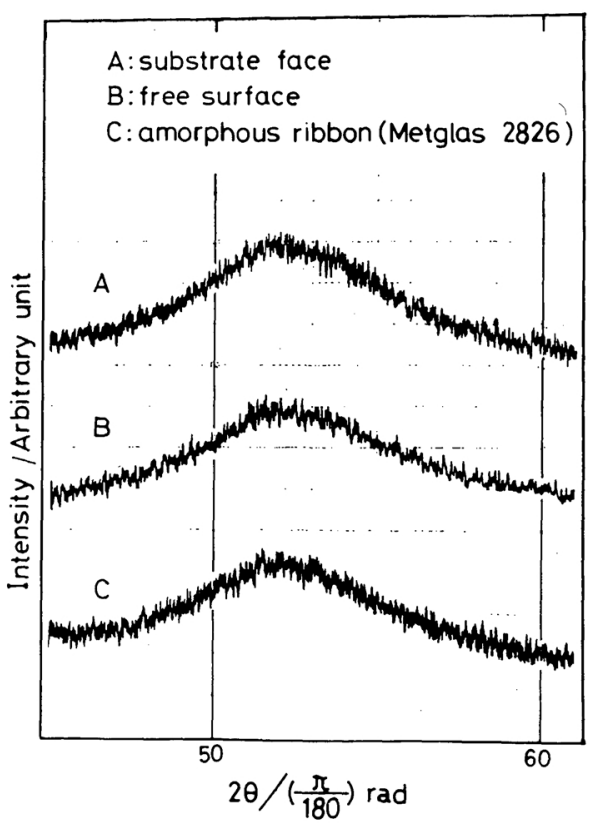

Fig. 8 X-ray diffraction patterns for the $\mathrm{Fe}_{40} \mathrm{Ni}_{40}$ $\mathrm{P}_{14} \mathrm{~B}_{6}$ alloy sheet spray-quenched under improved condition.

rate of liquid carbon dioxide was largely increased to $4.71 \mathrm{~g} / \mathrm{s}$ keeping the same conditions as those in case of B in Fig. 7.

Figure 8 exhibits $\mathrm{X}$-ray diffraction patterns for the quenched $\mathrm{Fe}_{40} \mathrm{Ni}_{40} \mathrm{P}_{14} \mathrm{~B}_{6}$ alloy sheet about $150 \mu \mathrm{m}$ in thickness thus obtained. Designations A and B were used for the free surface and the substrate face of the sheet product, respectively, and $\mathrm{C}$ for the amorphous ribbon, prepared by the Allied Chemical Co., of the same composition as that of the present alloy. As seen in the figure, both $\mathrm{A}$ and $\mathrm{B}$ clearly show halo-patterns typical of the amorphous material, and a diffraction pattern for any part of the free surface and the substrate face of the product was the same as the ones in this figure. Therefore, when the flow rate of the cryogen is increased as above, the effectiveness of quenching for the deposit alloy is considered to be strikingly raised. However, when the blow rate was increased still more than this, quenched alloy sheets began to exfoliate from the substrate. So it was impossible to prepare a thicker quenched sheet by increasing the blow rate like this. The upper limit of the effective blow rate of liquid carbon 
dioxide is about $4.70 \mathrm{~g} / \mathrm{s}$ in the present quenching system and hence the maximum thickness of quenched sheets obtained is considered to be about $150 \mu \mathrm{m}$. Such a quenching effect due to the carbon dioxide cryogen will be produced also in the cases in which other cold gases such as nitrogen gas cooled with liquid nitrogen are used.

Furthermore, the spray-quenched sheets revealing the halo-patterns in the X-ray analyses as shown in Fig. 8 were thermally examined by DSC as in case of the flaky samples described earlier. A typical DSC scan for such sample sheets is shown in Fig. 9. By analyzing the DSC curve like this in the same way as used for the flaky samples values of $T_{\mathrm{x}}$ and $\Delta H_{\mathrm{c}}$ were given to be $681 \mathrm{~K}$ and $-4.51 \mathrm{~kJ} / \mathrm{mol}$ respectively. These values are in excellent agreement with those earlier obtained for the flaky alloy. In addition, a measured value of the micro-Vickers hardness number (load: $0.49 \mathrm{~N}$ ) of the spray-quenched sheet was $690 \pm 60$. Since the hardness number is reported to be 640 in the literature ${ }^{(11)}$, the value measured in the present work seems to be consistent with the published datum within experimental error.

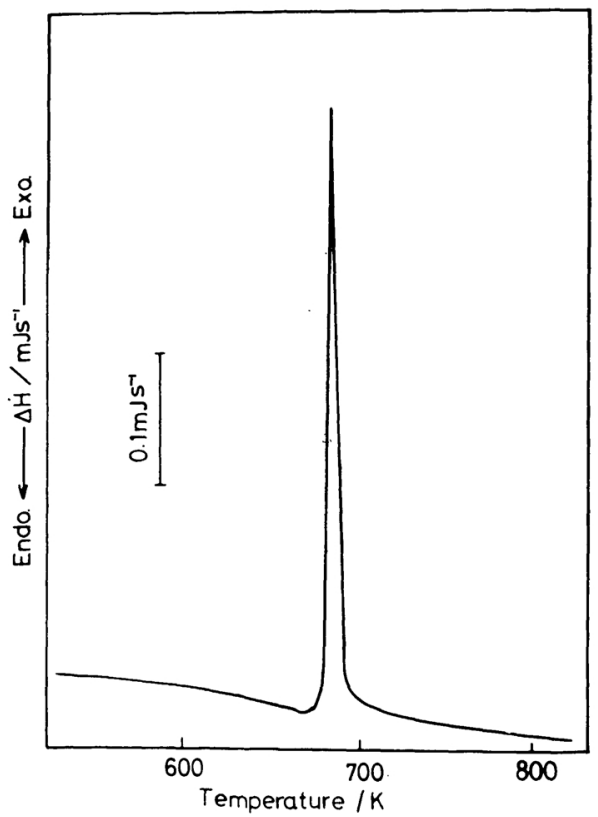

Fig. 9 DSC curve for the spray-quenched $\mathrm{Fe}_{40} \mathrm{Ni}_{40}$ $\mathrm{P}_{14} \mathrm{~B}_{6}$ alloy sheet revealing the typical amorphous halo-pattern in its X-ray analysis.
The spray-quenched sheet was also considerably ductile even in the thickness of about $150 \mu \mathrm{m}$; for instance, even after bending the sheet to form the radius of curvature of about $2 \mathrm{~mm}$, it immediately returned to the same flat form as the original one when its bending stress was removed.

In view of the above results of the X-ray and DSC analysis and the hardness measurement for the spray-quenched sheets, these $\mathrm{Fe}_{40} \mathrm{Ni}_{40} \mathrm{P}_{14} \mathrm{~B}_{6}$ alloy sheets are judged to be amorphous. Photograph 1 shows a typical $\mathrm{Fe}_{40} \mathrm{Ni}_{40} \mathrm{P}_{14} \mathrm{~B}_{6}$ alloy sheet thus obtained about $150 \mu \mathrm{m}$ in thickness, $130 \mathrm{~mm}$ in width, and $250 \mathrm{~mm}$ in length.

Although the sheet product is about $150 \mu \mathrm{m}$ thick, it is so porous as to be slightly transparent because of the presence of some undeposited regions in it. Therefore, for the production of denser and thicker amorphous sheets, first of all, thicker as-deposited sheets must be prepared, and then densification may be capable of being performed by such compression work as a rolling process in view of the considerable ductility $^{(12)}$ of amorphous alloys.

\section{Conclusions}

From the results of the study performed on the $\left(\mathrm{Fe}_{1-x} \mathrm{Ni}_{x}\right)_{80} \mathrm{P}_{14} \mathrm{~B}_{6}$ alloy system with $0.1 \leq$ $x \leq 0.9$ for production of amorphous alloys by flame-spray quenching, the following conclusions are drawn:

(1) The amorphous alloys of the present system can be produced in air by using the spray-quenching equipment consisting basically of the spray gun of oxyacetylene type and of

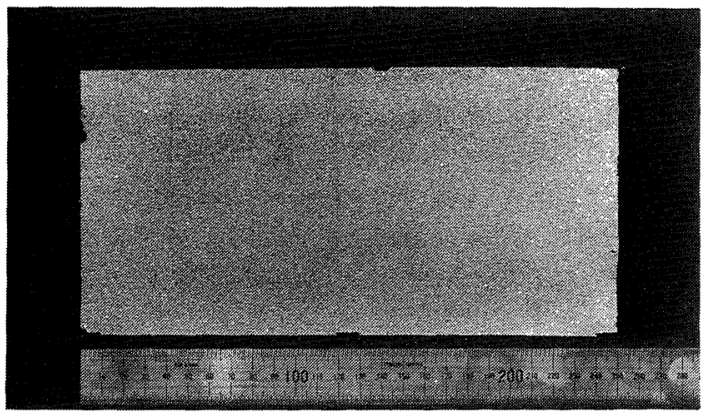

Photo. 1 Spray-quenched sheet $150 \mu \mathrm{m}$ thick of $\mathrm{Fe}_{40} \mathrm{Ni}_{40} \mathrm{P}_{14} \mathrm{~B}_{6}$ alloy (free surface). 
the water-cooled copper plate as a cold substrate.

(2) By controlling the gun traverse rate as fast as $0.70-1.00 \mathrm{~m} / \mathrm{s}$ and doing the argon gas blow around the flame at the rate of $8.00 \times 10^{-4}$ $\mathrm{m}^{3} / \mathrm{s}$ adequately to adjust the flame temperature as well as to suppress the oxidation of metal stream, the effect of quenching is remarkably improved. When these additional operations are performed on a series of nine kinds of the alloys with $0.1 \leq x \leq 0.9$ in this alloy system in the spray-quenching, amorphous flakes are easily obtained in all but the alloys with $x \leq 0.3$ whose quenched samples reveal some weak peaks indicating the slight crystallinity in the $\mathrm{X}$-ray diffraction patterns.

(3) Together with the additional opperations as above, when the liquid carbon dioxide blowing is carried out over all the substrate area at the rate of about $4.70 \mathrm{~g} / \mathrm{s}$, oxidation of the deposit alloy is prevented due to the carbon dioxide gas-shielding effect generated on the substrate, i.e., on quenched deposit alloy surface, and hence the effectiveness of quenching itself is strikingly improved. By such improvement of quenching, the amorphous sheet of the $\mathrm{Fe}_{40} \mathrm{Ni}_{40} \mathrm{P}_{14} \mathrm{~B}_{6}$ alloy with $x=0.5$ about $150 \mu \mathrm{m}$ in thickness can be prepared without difficulty.

(4) The flame-spray quenching method described in this paper appears capable of being applied also for production of thicker amorphous alloy sheets as well as their flakes in quantities in a wide variety of alloy systems, prepared to be homogeneous in composition, including the present alloy system by making further improvements on the spray-quenching equipment.

\section{Acknowledgements}

The authors wish to express their gratitude to Dr. M. Nakane, Mr. H. Suzuki, and Mr. I. Uehara of Government Industrial Research Institute, Osaka, for the kindly advice on the thermal analysis of amorphous alloys. They are also indebted to Professor P. H. Shingu of Kyoto University and Dr. K. Shimomura of Kyoto University (now at Hitachi Co., Ltd.) for the presentation of invaluable informations on amorphous alloys and to Lecturer $T$. Kitamura of Iron and Steel Technical College for his help in the measurement of brightness of amorphous sheets. Acknowledgement is gratefully made to Fukuda Metal Foil \& Powder Co., Ltd. for the preparation of alloy powder. Thanks are due also to Messrs. K. Akamatsu (now at Nippon Kokan K.K.), S. Fukunaga (now at Nippon Steel Corp.), S. Suzuki (now at Sumitomo Metal Industries, Ltd.), and H. Takko (now at Sumikin Welding Electrode Co., Ltd.), the graduates of Iron and Steel Technical College in the class of 1978, for their help in the experiment.

\section{REFERENCES}

(1) H. Miura, S. Isa and N. Tanigami: Collected Abstracts (in Japanese) of the 1978 Autumn Meeting of the Japan Institute of Metals, p. 227.

(2) H. Miura and S. Isa: Collected Abstracts (in Japanese) of the 1979 Spring Meeting of the Japan Institute of Metals, p. 187.

(3) B. C. Giessen, N. M. Madhava, R. J. Murphy, P. Ray and J. Surette: Met. Trans., 8A (1977), 364.

(4) P. H. Shingu, K. Shimomura and R. Ozaki: Trans. JIM, 20 (1979), 33.

(5) M. Moss: Acta Met., 16 (1968), 321.

(6) M. Moss and D. M. Schuster: Trans. ASM, 62 (1969), 201.

(7) K. D. Krishnanand and R. W. Cahn: Rapidly Quenched Metals, ed. by N. J. Grant and B. C. Giessen, MIT Press, (1976), p. 67.

(8) H. S. Chen and K. A. Jackson: Metallic Glasses, ASM, (1978), p. 74.

(9) D. E. Polk and H. S. Chen: J. Non-Crystalline Solids, 15 (1974), 165.

(10) F. Spaepen and D. Turnbull: Rapidly Quenched Metals, ed. by N. J. Grant and B. C. Giessen, MIT Press, (1976), p. 205.

(11) T. Masumoto: KINZOKU (in Japanese), (1975), No. 6, p. 59.

(12) L. A. Davis: Rapidly Quenched Metals, ed. by N. J. Grant and B. C. Giessen, MIT Press, (1976), p. 369 . 